\title{
Influence of synthetic and natural photosensitizers activated by photodynamic therapy on extrusion bond strength of fiber post to radicular dentin
}

\author{
Khalid H. Almadi ${ }^{1}$, Mazen F. Alkahtany², Basil Almutairi ${ }^{3}$
}

\begin{abstract}
Objective: To assess the effect of different photosensitizers activated by low-level laser therapy on EBS of glass fiber post to radicular dentin.

Methods: This study was conducted at King Saud University from January 2021 to March 202. Fifty maxillary central incisors were sanitized and decoronated. NiTi was used for mechanical instrumentation of the canal. All canals were shaped, cleaned and obturated with gutta-percha. Post space was made using peso reamers. Four Division of groups were made according to photosensitizers used $(n=10)$. Group-1: MBP at $100 \mathrm{mg} / \mathrm{l}$, Group-2: Phycocyanin at $100 \mathrm{mg} / \mathrm{l}$, Group-3: CP at $500 \mathrm{mg} / \mathrm{l}$, and Group-4 toluidine blue photosensitizer (TB). Lasers were used for activation of photosensitizers. In Group- 5 samples were irrigated using sodium hypochlorite $\mathrm{NaOCl}+17 \%$ EDTA. Posts were cemented and teeth sectioned into apical, coronal and middle. For EBS all samples were subjected to a universal testing machine. Fracture patterns were analyzed using stereomicroscope. To compare EBS at different segments One-way analysis of variance (ANOVA) and Tukey multiple comparison tests $(p=0.05)$ was performed.

Results: The maximum value of EBS was shown in Group-2 radicular canal treated with CP with 17\% EDTA at all three levels cervical $(8.61 \pm 1.32 \mathrm{MPa})$, middle $(6.81 \pm 0.73 \mathrm{MPa})$, and apical $(5.51 \pm 0.25 \mathrm{MPa})$. Similarly, the minimum value of EBS was displayed in Group-5 canal irrigated with $2.25 \% \mathrm{NaOCl}+17 \%$ EDTA (control) coronal $(6.10 \pm 1.77 \mathrm{MPa})$, middle $(5.11 \pm 0.75 \mathrm{MPa})$, and apical $(3.60 \pm 0.94 \mathrm{MPa})$. Intragroup assessment disclosed a decrease in EBS from cervical one-third to apical one-third in all groups

Conclusion: P, CP, and TB along with EDTA have the potential to be used as canal disinfectant and favors the bonding of GFP to radicular dentin using self-etch adhesive resin.
\end{abstract}

KEYWORDS: Photodynamic therapy, Photosensitizers, Extrusion bond strength, Radicular dentin.

doi: https://doi.org/10.12669/pjms.37.7.4331

How to cite this:

Almadi KH, Alkahtany MF, Almutairi B. Influence of synthetic and natural photosensitizers activated by photodynamic therapy on extrusion bond strength of fiber post to radicular dentin. Pak J Med Sci. 2021;37(7):1912-1917.

doi: https://doi.org/10.12669/pjms.37.7.4331

This is an Open Access article distributed under the terms of the Creative Commons Attribution License (http://creativecommons.org/licenses/by/3.0), which permits unrestricted use, distribution, and reproduction in any medium, provided the original work is properly cited.

\section{INTRODUCTION}

Correspondence:

Khalid H. Almadi

Department of Restorative Dental Sciences,

Division of Endodontics,

College of Dentistry,

King Saud University,

Riyadh, Saudi Arabia.

Email. kalmadi@ksu.edu.sa

* Received for Publication:

* $1^{\text {st }}$ Revision Received:

* $2^{\text {nd }}$ Revision Received:

* Final Revision Accepted:
March 4, 2021

April 12, 2021

May 31, 2021

September 9, 2021
The success of root canal treatment is reliant on the reduction of microbial growth through irrigating solutions, proper instrumentation, and canal medicaments. ${ }^{1}$ Ideally sodium hypochlorite $(\mathrm{NaOCl})$ at different concentrations is considered to be an irrigant of choice for canal disinfection along with ethylene diamine tetra-acetic acid (EDTA) to remove the smear layer after instrumentation. The smear layer is permeable to toxins, composed of organic and inorganic debris, and dwells bacteria. Current evidence advocates that it's necessary to 
remove the smear layer before fiber postcementation to encourage close adaptation and penetration of cement in dentinal tubules. ${ }^{2}$ Moreover, available literature proclaims that though $\mathrm{NaOCl}$ as a canal irrigant minimizes bacterial load it has a detrimental effect on the internal wall of radicular dentin compromising the adhesion of fiber post..$^{3-6}$

An alternative substitute for canal disinfection is photodynamic therapy (PDT) using different photosensitizers. Natural i.e., curcumin photosensitizer (CP) and chemically made photosensitizers i.e., methylene blue photosensitizer (MBP) has been already used in dentistry. MBP and $C P$ are used in canal disinfection, on carries affected dentin (CAD), and as dentin and enamel conditioner and have shown promising outcome. ${ }^{7-9}$ However work by Sayhon et al., advocates that $\mathrm{CP}$ has an unfavorable effect on mechanical properties of dentin and it does not improve bond values of fiber post. ${ }^{10}$ Similarly, Strazzi Sayhon in his sequel study asserted that MBP for canal disinfection descends the bond value of fiber post to dentin. ${ }^{11}$

PDT works on the principle of absorption of a photon from a low-intensity visible light source resulting in reactive oxygen species (ROS) instigating lysis of bacterial cell wall through the process of oxidation. ${ }^{8}$ Ideally a photosensitizer should exhibit a low toxic effect on to host cell, produce ROS in a short period, water-soluble, and have an appropriate shelf life. None of the available photosensitizers confirm all the characteristics. But the available evidence suggests that toluidine blue (TB) and Phycocyanin (P) closely fall to these characteristics but their use in dentistry is scarce and not reported. ${ }^{8,9}$

To our knowledge from indexed literature, use of $\mathrm{CP}$ and MBP as canal disinfectant have shown to give conflicting outcomes. Moreover, the use of $P$ and TB in sepsis of post space is still unprecedented. It is hypothesized that the use of conventional canal irrigant with EDTA will exhibit better extrusion bond values (EBS) at all three levels i.e., coronal, apical, middle apical compared to contemporary antimicrobial PDT+EDTA. Therefore, the present study aimed to assess the effect of different photosensitizers activated by low-level laser therapy on EBS of glass fiber post to radicular dentin.

\section{METHODS}

Fifty maxillary central incisors were collected from clinical settings over 180 days. Teeth having a fracture, curved roots, or cracks were excluded.
To maintain homogeneity, teeth having a canal length of $18 \mathrm{~mm}$ and diameter of $2 \mathrm{~mm}$ were placed in $0.5 \%$ thymol solution for disinfection at $4^{\circ} \mathrm{C}$ for 72 hours. Decoronation of the teeth was done up to the cement-o-enamel junction buccolingually using a low-speed diamond saw (IsoMet 5000; Buehler). The study was conducted in King Saud University from January 2021 to March 2021under the approval of the Institutional review board number E-21-5829 and was reported following checklist for reporting invitro study (CRIS) guidelines.

Teeth were treated endodontically using $\mathrm{K}$ file\#80 (Maillefer Instruments, Tulsa, USA). 1mm short of working length. Instrumentation of the canal was done mechanically via crown down technique using NiTi protaper system (Dentsply Maillefer). The shaping of the canal was done using S1, S2, and SX. The armamentarium of finishing files consisted of F1 and F2. During the cleaning and shaping process, the entire canal length was irrigated constantly using $1 \%$ sodium hypochlorite. Using paper points (Gapa Dent, Zhengzhou Smile Dental Equipment, Henan, PRC) the canal length was dried. Cone-shaped GP (Gapa Dent, India) along with sealers AH Plus (Dentsply, Konstanz, Germany) were used to fill the post space via lateral condensation. Peso reamer (Mani, ZZlinker, Shingai) \# 4,3,2 was used to prepare post space.

Using K files \#80 (Maillefer Instruments, Tulsa, OK, USA) teeth were treated endodontically $1 \mathrm{~mm}$ short of working length. Using a protaper NiTi system (Dentsply Maillefer) via crown down technique mechanical instrumentation of the canal was done. The canal was shaped using S1, S2, SX shaping files and F1 and F2 finishing files following by constant irrigation with $1 \%$ sodium hypochlorite solution $(8 \mathrm{ml})$. Paper points (Gapa Dent, Zhengzhou Smile Dental Equipment, Henan, PRC) were used to dry canals. Using a technique of lateral compaction canals were obturated with gutta-percha (Gapa Dent) and sealers AH Plus (Dentsply, Konstanz, Germany). All samples were kept in 100\% humidification for seven days at $37^{\circ} \mathrm{C}$. Samples were placed vertically up to cement o enamel junction in polyvinyl pipes of diameter $4 \mathrm{~mm}$ using cold cure acrylic resin. Post spacing was created using peso reamers (Mani, ZZlinker, Shingai) with numbers \# 4,3, and 2 . To handle the procedure professionally, recommended drills by the manufacturer of a number 100 fiber posts (Dentoclic glass fiber post) to a length of $10 \mathrm{~mm}$ were 
used. All specimens were divided into five groups $(n=10)$ based on the type of photosensitizer (PS) and conventional method on canal disinfection.

Samples in Group-1 and Group-3: The canal was filled using methylene blue photosensitizer (MBP) 100mg/L (Sisco Research Lab. Pvt. Ltd, Maharashtra, India) prepared in $2 \%$ aqueous solution. A diode laser having a wavelength of $810 \mathrm{~nm}$ was used to activate PS MBP. Irradiation time for the activation of oxygen species $\left(\mathrm{O}_{2}\right)$ was $300 \mathrm{sec}$ for MBP. Whereas, Curcumin PS in Group-3, was activated by $240 \mathrm{sec}$. of blue LED light (Clear Blue Digi 2.0) $(\lambda 480 \mathrm{~nm})$ irradiation. CP was used in a concentration of $50 \mathrm{mg} / \mathrm{L}$. A flexible fibre optic was used throughout the length of the canal for homogenous free radical formation. Seventeen percent EDTA was used to remove the smear layer throughout the canal length for $180 \mathrm{sec}$.

Samples in Group-2 and Group-4: Phycocyanine $(\mathrm{P})$ powder (Photoactive + , Weber medical, Germany) and Toluidine blue (TB) (Blue $+\mathrm{T}$, Novateb, Iran) were prepared freshly in an aqueous solution of concentration $100 \mathrm{mg} / \mathrm{L}$ each. TB and $\mathrm{P}$ were poured in the canal length and were activated using a 635-nm diode laser (Konftec, Taiwan) with an output of $220 \mathrm{~mW}$ in continuous mode for $180 \mathrm{sec}$. The power density of the device was $0.33 \mathrm{w} / \mathrm{cm} 2$. Laser power was checked with a power meter (Coherent, USA) before experiments. $17 \%$ EDTA was used to remove the smear layer throughout the canal length for 180 sec. (Table-I).

Samples in Group-5: The specimens in Group-5 were irrigated using $2.25 \%$ sodium hypochlorite $(\mathrm{NaOCl})$ (Vishal DentoCare Private, Ltd, India) and 17\% EDTA (Pulpdent Corporation, Watertown using a disposable needle syringe of 25 gauge in a to and fro motion $1 \mathrm{~mm}$ short of working length.

After canal disinfection in all groups. qll specimens were washed using distilled water and dried using paper points.70\% ethanol was used to clean the glass fiber post (GFP) (Swastik Dentomed Device, India) and fitted in the canal.
The canal space was filled with self-etch resin cement Rely X Unicem (3M ESPE, St. Paul, MN, USA) and light-cured (LED B Woodpecker Light Cure Suz - Dent (India) Private Limited) using blue halogen light for 30 secone. For 48 hours all specimens were placed in the humid environment before performing EBS testing

Using a diamond bur all samples were sectioned (1 mm segment each) into coronal, middle, and apical. A total of 180 segments were prepared from 50 samples. For EBS all samples were subjected to a universal testing machine $(1 \mathrm{~mm} / \mathrm{min})$ (Zwick/ Roell Z050, Germany. Force was applied in a coronal apical direction. The force required to debond the fiber post from radicular dentin was measured in megapascal (MPa).

$$
\begin{gathered}
\text { Debond stress }=\mathrm{N} / \mathrm{mm}^{2} \\
\hline \mathrm{N}=\text { maximum failure load and } \\
\mathrm{mm}^{2}=\text { bonding area of post segment }
\end{gathered}
$$

Using stereomicroscope at 50x magnification fracture patterns of debonded surfaces were analyzed. The patterns of fracture were categorized into cohesive, adhesive, and admixed. One-way analysis of variance (ANOVA) and Tukey multiple comparison tests $(p=0.05)$ was done to compare EBS at different segments of the root structure.

\section{RESULTS}

The highest extrusion bond strength (EBS) was shown in Group-2 radicular canal treated with CP with $17 \%$ EDTA at all three levels cervical $(8.61 \pm 1.32 \mathrm{MPa})$, middle $(6.81 \pm 0.73 \mathrm{MPa})$, and apical $(5.51 \pm 0.25 \mathrm{MPa})$. Similarly, the lowest EBS was displayed in Group-5 canal irrigated with $2.25 \% \mathrm{NaOCl}+17 \%$ EDTA (control) coronal $(6.10 \pm 1.77 \mathrm{MPa})$, middle $(5.11 \pm 0.75 \mathrm{MPa})$, and

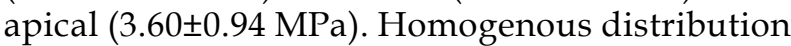
of data was assessed using Leven's test. EBS values of all groups were presented in Table-II.

Intragroup assessment disclosed a decrease in EBS from cervical one-third to apical one-third in all experimental groups. At the apical region, a

Table-I: Details regarding photosensitizers used in the present study.

\begin{tabular}{lllcc}
\hline Class & Example & Charge & $\begin{array}{c}\text { Excitation } \\
\text { Maximum }(n m)\end{array}$ & $\begin{array}{c}\text { The concentration } \\
\text { of PS mg/L }\end{array}$ \\
\hline \multirow{2}{*}{ Phenothiazinium } & Methylene blue & Cationic & 632 & 100 \\
& Toluidine blue & Cationic & 410 & 100 \\
& Curcumin & Neutral & 547 & 500 \\
\cline { 2 - 3 } Natural Photosensitizers (PS) & Phycocyanin & Neutral & 670 & 100 \\
\hline
\end{tabular}


Table-II: Means and Standard deviations (SD) of extrusion bond strength (MPa) values among experimental groups at cervical, middle, and apical levels of root.

\begin{tabular}{lccc}
\hline Groups & Cervical & Middle & Apical \\
\hline $\begin{array}{l}\text { Group-1: } \\
\text { Methylene blue photosensitizer (MBP) }+17 \% \text { EDTA }\end{array}$ & $6.54 \pm 0.21^{\mathrm{b}, \mathrm{A}}$ & $5.59 \pm 0.41^{\mathrm{b}, \mathrm{A}}$ & $3.62 \pm 0.78^{\mathrm{b}, \mathrm{B}}$ \\
$\begin{array}{l}\text { Group-2: } \\
\text { Phycocyanin }(\mathrm{P})+17 \% \text { EDTA }\end{array}$ & $8.21 \pm 0.35^{\mathrm{a}, \mathrm{A}}$ & $6.21 \pm 1.28^{\mathrm{a}, \mathrm{A}}$ & $5.13 \pm 0.22^{\mathrm{a}, \mathrm{B}}$ \\
$\begin{array}{l}\text { Group-3: } \\
\text { Curcumin photosensitizer }(\mathrm{CP})(\mathrm{CP})+17 \% \text { EDTA }\end{array}$ & $8.61 \pm 1.32^{\mathrm{a}, \mathrm{A}}$ & $6.81 \pm 0.73^{\mathrm{a}, \mathrm{A}}$ & $5.51 \pm 0.25^{\mathrm{a}, \mathrm{B}}$ \\
$\begin{array}{l}\text { Group 4: } \\
\text { Toluidine Blue photosensitizer }(\mathrm{TB})+17 \% \text { EDTA }\end{array}$ & $8.51 \pm 0.74^{\mathrm{a}, \mathrm{A}}$ & $6.95 \pm 0.91^{\mathrm{a}, \mathrm{A}}$ & $5.18 \pm 0.74^{\mathrm{a}, \mathrm{B}}$ \\
$\begin{array}{l}\text { Group-5: } \\
\text { 2.25\% NaOCl }+17 \% \text { EDTA (control) }\end{array}$ & $6.10 \pm 1.7^{7 \mathrm{~b}, \mathrm{~A}}$ & $5.11 \pm 0.75^{\mathrm{b}, \mathrm{A}}$ & $3.60 \pm 0.9^{4 \mathrm{~b}, \mathrm{~B}}$ \\
\hline
\end{tabular}

Different superscript lower-case alphabets denote statistically significant difference within same column $(\mathrm{p}<0.05)$,

Data with different upper-case alphabets denotes significant difference within each row. $(\mathrm{p}<0.05)$.

statistically significant difference was displayed in comparison to middle and cervical root sections among all groups $(\mathrm{p}<0.05)$.

Intergroup comparison unveiled comparable extrusion bond strength in control group canal disinfected with $2.25 \% \mathrm{NaOCl}$ with $17 \%$ EDTA and Group-1 post space disinfected using MBP at all three levels of root structure coronal, middle, and apical. Similarly, samples in Group 2, 3, and 4

Table-III: Fracture Pattern according to failure type.

\begin{tabular}{llccc}
\hline Groups & $\begin{array}{l}\text { Root } \\
\text { segment }\end{array}$ & $\begin{array}{c}\text { Cement/ } \\
\text { Dentin } \\
\text { Adhesive }\end{array}$ & $\begin{array}{c}\text { Cement/ } \\
\text { Post } \\
\text { Cohesive }\end{array}$ & Admixed \\
\hline \multirow{6}{*}{ Group-1 } & Coronal & $60 \%$ & $10 \%$ & $30 \%$ \\
& Middle & $70 \%$ & $10 \%$ & $20 \%$ \\
& Apical & $70 \%$ & $20 \%$ & $10 \%$ \\
Group-2 & Coronal & $30 \%$ & $60 \%$ & $10 \%$ \\
& Aiddle & $80 \%$ & $10 \%$ & $10 \%$ \\
& Apical & $70 \%$ & $20 \%$ & $10 \%$ \\
Group-3 & Coronal & $30 \%$ & $50 \%$ & $20 \%$ \\
& Middle & $50 \%$ & $30 \%$ & $30 \%$ \\
& Apical & $70 \%$ & $10 \%$ & $20 \%$ \\
Group-4 & Coronal & $10 \%$ & $20 \%$ & $70 \%$ \\
& Middle & $50 \%$ & $20 \%$ & $30 \%$ \\
& Apical & $90 \%$ & $10 \%$ & $10 \%$ \\
& Coronal & $70 \%$ & - & $30 \%$ \\
Group-5 & Middle & $50 \%$ & $20 \%$ & $30 \%$ \\
& Apical & $80 \%$ & $10 \%$ & $10 \%$ \\
\hline \multirow{6}{*}{ Gen }
\end{tabular}

canal space disinfected with Phycocyanin $(\mathrm{P})$ with $17 \%$ EDTA, CP with 17\% EDTA and Toluidine Blue photosensitizer (TB) $+17 \%$ EDTA displayed statistically significant difference to control and specimens in Group- 1 at all three levels $(p<0.05)$.

Forty-five failures were observed between dentin and adhesive interface. Failure between adhesive and cement interface was dominant among all interventional groups. Adhesive failure was followed by post cement failure type i.e., cohesive.

\section{DISCUSSION}

The current study was assumed on the hypothesis that the use of conventional canal irrigant with EDTA will exhibit better extrusion bond values (EBS) at all three levels i.e., coronal, apical, middle compared to contemporary antimicrobial PDT+EDTA. To our surprise, a partial acceptance of the supposition was noted as antimicrobial PDT using $\mathrm{CP}, \mathrm{P}$ and TB displayed better EBS to conventional $2.25 \% \mathrm{NaOCl}+17 \%$ EDTA and MBP at all three levels of canal length. The bond power between GFP and radicular dentin was assessed using EBS. The test is dependable as it replicates oral condition and transmits stress equally along the long axis of radicular dentin. ${ }^{12,13}$ The test has a low failure rate, is highly sensitive and measures three different portions from a single root structure. It also provides a comparative analysis with other investigational groups. ${ }^{14}$

In the present study, two different classes of photosensitizers were assessed. MBP and TB from class Phenothiazinium whereas, $\mathrm{CP}$ and $P$ from natural class photosensitizers. Both natural photosensitizers (CP [Coronal 8.61 \pm 1.32 
$\mathrm{MPa}$; middle $6.81 \pm 0.73 \mathrm{MPa}$; apical $5.51 \pm 0.25$ $\mathrm{MPa}$ ) and (P [Coronal $8.21 \pm 0.35 \mathrm{MPa}$; middle 6.21 $\pm 1.28 \mathrm{MPa}$; apical $5.13 \pm 0.22 \mathrm{MPa}$ ) showed comparable EBS at all levels of radicular dentin. The production of singlet oxygen varies for every different photosensitizer. ${ }^{15}$ The quantity of singlet oxygen is measured by quantum yields. Literature reports that $\mathrm{P}$ when activated has the lowest oxygen production with quantum yields hence it does not interfere with the polymerization of resin to radicular dentin favoring increase bond values. ${ }^{16}$ Moreover, $\mathrm{CP}$ having an anionic nature binds with Calcium $(\mathrm{Ca}++)$ in radicular dentin encouraging retention of fibre post to dentin structure. ${ }^{10}$ Since, both natural photosensitizers (CP and $\mathrm{P})$ are hydrophobic and polyphenolic these characteristics might have attributed to improving EBS. ${ }^{7}$ These outcomes should be implemented in the clinical setting with caution as still use of $\mathrm{P}$ is unprecedented in dentistry. Apart from natural photosensitizers, TB (coronal $8.51 \pm 0.74 \mathrm{MPa}$, middle $6.95 \pm 0.91 \mathrm{MPa}$, apical $5.18 \pm 0.74 \mathrm{MPa})$ an artificial photosensitizer displayed bond values comparable to $\mathrm{CP}$ and P. A logical explanation for this outcome is TB at this concentration $(100 \mathrm{mg} / \mathrm{l})$ when activated at $638 \mathrm{~nm}$ wavelength, might have boosted cross-linking of collagen fibrils in the dentin to resin providing a better outcome. ${ }^{17,18}$ Moreover, diffusion capacity of $\mathrm{TB}$, hydrophobic nature and light energy fluency of TB may have resulted in favorable EBS.

Among all the photosensitizers MBP had the lowest EBS at all three parts of the root segment (coronal 6.54 $\pm 0.21 \mathrm{MPa}$; middle $5.59 \pm 0.41 \mathrm{MPa}$ and apical $3.62 \pm 0.78 \mathrm{MPa})$. MBP is cationic. Its affinity with anionic molecules in dentin i.e., calcium and phosphate might cause precipitation on the dentinal walls deteriorating EBS. ${ }^{19,20}$ Furthermore, MB is hydrophilic. The hydrophilicity of MB at a higher concentration may influence the absorption of water from inter and intratubular part of dentin compromising EBS. ${ }^{20,21}$ These explanations have already been discussed by Sayhon et al. ${ }^{19}$

A descend in EBS values was observed among all investigated groups. Poor penetration of photosensitizers, variations in the anatomy of root structure, small dense and less dentinal tubules at the apical region may have contributed to this outcome. ${ }^{22,23}$ Cement dentin interface failure was observed in the majority of all the samples, suggesting interface to be the weakest between post and radicular dentin. ${ }^{22,23}$
Limitations of the study: Within the limitations of the study, atomic force microscopy of radicular dentin structure pre- and post-photosensitizers usage needs assessment. Moreover, topographic analysis of dentin and its effect after using different photosensitizers along with their effect on the micromechanical structure requires further valuation. De bonded surfaces should be assessed using dispersive spectroscopy. More clinical and lab-based studies need to be performed to extrapolate the findings of the present study.

\section{CONCLUSION}

$\mathrm{P}, \mathrm{CP}$, and TB along with EDTA have the potential to be used as canal disinfectant and favors the bonding of GFP to radicular dentin using self-etch adhesive resin. Use of MBP and conventional method of canal disinfection using $2.25 \% \mathrm{NaOCl}+17 \%$ EDTA should be used with cautions in dental clinical settings.

Acknowledgement: The authors would like to thank the College of Dentistry Research Centre and Deanship of Scientific Research at King Saud University, Saudi Arabia, for supporting this project (E-21-5829).

\section{Conflict of Interest Statement: None.}

\section{REFERENCES}

1. Maroulakos G, He J, Nagy WW. The Post-endodontic Adhesive Interface: Theoretical Perspectives and Potential Flaws. J Endod. 2018;44(3):363-371. doi: 10.1016/j.joen.2017.11.007

2. Tani C, Finger WJ. Effect of smear layer thickness on bond strength mediated by three all-in-one self-etching priming adhesives. J Adhes Dent. 2002;4(4):283-289. http:// www.ncbi.nlm.nih.gov/pubmed/12675016 (Accessed January 19, 2020)

3. Baumgartner JC, Johal S, Marshall JG. Comparison of the Antimicrobial Efficacy of $1.3 \% \mathrm{NaOCl} / \mathrm{BioPure}$ MTAD to $5.25 \% \mathrm{NaOCl} / 15 \%$ EDTA for Root Canal Irrigation. J Endod. 2007;33(1):48-51. doi: 10.1016/j.joen.2006.08.007

4. Zehnder M. Root Canal Irrigants. J Endod. 2006;32(5):389398. doi: 10.1016/j.joen.2005.09.014

5. Seballos VG, Barreto MS, da Rosa RA, Machado E, Valandro LF, Kaizer OB. Effect of post-space irrigation with $\mathrm{NaOCL}$ and $\mathrm{CaOCL}$ at different concentrations on the bond strength of posts cemented with a selfadhesive resin cement. Braz Dent J. 2018;29(5):446-451. doi: 10.1590/0103-6440201801955

6. Bitter K, Hambarayan A, Neumann K, Blunck U, Sterzenbach G. Various irrigation protocols for final rinse to improve bond strengths of fiber posts inside the root canal. Eur J Oral Sci. 2013;121(4):349-354. doi: 10.1111/eos.12057

7. Alrahlah A, Naseem M, Tanveer SA, Abrar E, Charania A, AlRifaiy $M Q$, et al. Influence of disinfection of caries effected dentin with different concentration of silver diamine fluoride, curcumin and Er, Cr:YSGG on adhesive bond strength to resin composite. Photodiagnosis Photodyn Ther. 2020;32. doi: 10.1016/j.pdpdt.2020.102065 
8. Al Deeb L, Bin-Shuwaish MS, Abrar E, Naseem M, AlHamdan RS, Maawadh AM, et al. Efficacy of chlorhexidine, Er Cr YSGG laser and photodynamic therapy on the adhesive bond integrity of caries affected dentin. An in-vitro study. Photodiagnosis Photodyn Ther. 2020;31:101875. doi: 10.1016/j.pdpdt.2020.101875

9. Alshahrani A, Abrar E, Maawadh AM, Al-Hamdan, R.S., Almohareb, T., AlFawaz, Y. et al. Management of caries affected dentin (CAD) with resin modified glass ionomer cement (RMGIC) in the presence of different caries disinfectants and photosensitizers. Photodiagnosis Photodyn Ther. 2020;32:101978. doi: 10.1016/j.pdpdt.2020.101978

10. Strazzi Sahyon HB, Silva PP da, Oliveira MS de, Cintra, LTA, Dezan-Júnior, E., Gomes-Filho, et al. Influence of curcumin photosensitizer in photodynamic therapy on the mechanical properties and push-out bond strength of glass-fiber posts to intraradicular dentin. Photodiagnosis Photodyn Ther. 2019;25:376-381. doi: 10.1016/j.pdpdt.2019.01.025

11. Strazzi-Sahyon HB, de Oliveira MS, da Silva PP, Banci HA, de Melo FS, Martinez CMT, et al. Does photodynamic therapy with methylene blue affect the mechanical properties and bond strength of glass-fiber posts in different thirds of intraradicular dentin? Photodiagnosis Photodyn Ther. 2020;30:101673. doi: 10.1016/j.pdpdt.2020.101673

12. Lan M, Zhao S, Liu W, Lee CS, Zhang W, Wang P. Photosensitizers for Photodynamic Therapy. Adv Healthc Mater. 2019;8(13): 347-364. doi:10.1002/adhm.201900132

13. Alkhudhairy F, Naseem M, Ahmad ZH, Alnooh AN, Vohra F. Influence of photobio-modulation with an Er,Cr: YSGG laser on dentin adhesion bonded with bioactive and resin-modified glass ionomer cement. J Appl Biomater Funct Mater. 2019;17(4):254-259. doi: $10.1177 / 2280800019880691$

14. Alkhudhairy F, Al-Johany SS, Naseem M, Bin-Shuwaish M, Vohra F. Dentin bond strength of bioactive cement in comparison to conventional resin cement when photosensitized with Er,Cr:YSGG laser. Pak J Med Sci. 2020;36(2):85-90. doi:10.12669/pjms.36.2.1284

15. Alkhudhairy F, Vohra F, Naseem M. Influence of Er,Cr:YSGG Laser Dentin Conditioning on the Bond Strength of Bioactive and Conventional Bulk-Fill Dental Restorative Material. Photobiomodulation, Photomedicine Laser Surg. 2020;38(1):30-35. doi: 10.1089/ photob.2019.4661

16. Akram Z, Shafqat SS, Niaz MO, Raza A, Naseem M. Clinical efficacy of photodynamic therapy and laser irradiation as an adjunct to open flap debridement in the treatment of chronic periodontitis: A systematic review and meta-analysis. Photodermatol Photoimmunol Photomed. 2020;36(1):3-13. doi: 10.1111/phpp.12499

17. Caires CSA, Silva CM, Lima AR, Alves LM, Lima THN, Rodrigues ACS, et al. Photodynamic inactivation of methicillin-resistant staphylococcus aureus by a natural food colorant (e-141II). Molecules. 2020;25(19):4464. doi: 10.3390/ molecules25194464

18. Strazzi Sahyon HB, Silva PP da, Oliveira MS de, Cintra LTA., Dezan-Júnior E, Gomes-Filho JE, et al. Influence of curcumin photosensitizer in photodynamic therapy on the mechanical properties and push-out bond strength of glassfiber posts to intraradicular dentin. Photodiagnosis Photodyn Ther. 2019;25:376-381. doi: 10.1016/j.pdpdt.2019.01.025

19. Chiniforush N, Pourhajibagher M, Shahabi S, Bahador A. Clinical approach of high technology techniques for control and elimination of endodontic microbiota. J Lasers Med Sci. 2015;6(4):139-150. doi: 10.15171/jlms.2015.09
20. Nielsen HK, Garcia J, Væth M, Schlafer S. Comparison of riboflavin and toluidine blue $\mathrm{O}$ as photosensitizers for photoactivated disinfection on endodontic and periodontal pathogens in vitro. Hamblin $\mathrm{M}$, ed. PLoS One. 2015;10(10):e0140720. doi: 10.1371/journal.pone.0140720

21. Sahyon HBS, da Silva PP, de Oliveira MS, Cintra LTA, Gomes-Filho JE, Santos PHD, et al. Effect of photodynamic therapy on the mechanical properties and bond strength of glass-fiber posts to endodontically treated intraradicular dentin. J Prosthet Dent. 2018;120(2):317.e1-317.e7. doi: 10.1016/j.prosdent.2018.05.009

22. Di Hipólito V, Rodrigues FP, Piveta FB, da Cunha Azevedo L, Alonso RCB, Silikas N, et al. Effectiveness of self-adhesive luting cements in bonding to chlorhexidine-treated dentin. Dent Mater. 2012;28(5):495-501. doi: 10.1016/j.dental.2011.11.027

23. Praditya D, Kirchhoff L, Bruning J, Rachmawati H, Steinmann J, Steinmann E. Anti-infective properties of the golden spice curcumin. Front Microbiol. 2019;10:912. doi: 10.3389 /fmicb.2019.00912

24. Alonaizan FA, Alofi RS, Alfawaz YF, Alsahhaf A, AlAali KA, Vohra F, et al. Effect of Photodynamic Therapy, Er,Cr:YSGG, and Nd:YAG Laser on the Push-Out Bond Strength of Fiber Post to Root Dentin. Photobiomodulation Photomedicine Laser Surg. 2020;38(1):24-29. doi: 10.1089/ photob.2019.4687

25. Kirmali O, Ustun O, Kapdan A, Kuştarc1 A. Evaluation of Various Pretreatments to Fiber Post on the Push-out Bond Strength of Root Canal Dentin. J Endod. 2017;43(7):1180-1185. doi: 10.1016/j.joen.2017.03.006

\section{Authors' Contribution:}

KHA, BA MFA: Data collection, study design, manuscript writing, final manuscript approval.

KHA, BA: Data collection, manuscript approval, and data interpretation.

KHA, MFA: Data collection, writing, revision of the manuscript, editing, and final manuscript approval. All authors are responsible and accountable for the accuracy and integrity of the work.

Authors:

1. Khalid H. Almadi, BDS, MS, FRCD(c) Department of Restorative Dental Science, Division of Endodontics,

2. Mazen F. Alkahtany, BDS, MS, FRCD(c) Department of Restorative Dental Science, Division of Endodontics,

3. Basil Almutairi, BDS, MSD, ABOD Department of Restorative Dental Science, Operative Division,

1-3: College of Dentistry,

King Saud University,

Riyadh, Saudi Arabia. 